\title{
Pseudocercospora piperis associated with leaf spots on Piper aduncum in Brazil
}

\author{
Fabiano Branco Rocha • Rogério Eiji Hanada • \\ Samlla Toledo de Albuquerque • Robert Weingart Barreto
}

Received: 1 April 2013 / Accepted: 3 June 2013 / Published online: 4 July 2013

(C) Australasian Plant Pathology Society Inc. 2013

\begin{abstract}
Piper aduncum (Piperaceae) is a neotropical plant that has been widely exploited as a medicinal plant in its native range but has recently become an important invasive plant species in Papua New Guinea. A cercosporoid fungus was recently found associated with leaf spots on this plant in the Amazon. The morphology of the fungus is typical of Pseudocercospora piperis, a fungus that has never been recorded on this host species in Brazil.
\end{abstract}

Keywords Cercosporoid · Mycosphaerellaceae ·

Piperaceae · Taxonomy

Piper aduncum L. (aperta-ruão, pimento-de-macaco, amongst many other common names in Brazil) is widely used in folk medicine, and is known to have antimicrobial (MorandimGiannetti et al. 2010) and insecticidal (Misni et al. 2011) properties. It is a perennial and erect shrub with articulate stalk originally occurring under the shade of tropical forests in Central and South America (Lorenzi 2000). In its native ranges it is never a dominant species, however Piper aduncum has been recently reported as an invasive species in Papua New Guinea (Hartemink 2010) probably owing to the absence of natural enemies in the exotic situation. Fungal pathogens associated with Piper aduncum may become of relevance for classical biological control. Nevertheless, little is known about the mycobiota of Piper aduncum in Brazil. Recently a fungus was found in association with severe spotting of leaves of Piper aduncum on the campus of the Instituto Nacional de Pesquisas da Amazônia (INPA),

F. B. Rocha $(\varangle) \cdot$ S. T. de Albuquerque $\cdot$ R. W. Barreto Departamento de Fitopatologia, Universidade Federal de Viçosa, 36570-00 Viçosa, Minas Gerias, Brazil

e-mail: rochafb@gmail.com

R. E. Hanada

Instituto Nacional de Pesquisas da Amazônia, Coordenação de

Tecnologia e Inovação, 69083-000 Manaus, Amazonas, Brazil
Manaus, state of Amazonas, Brazil. The fungus was readily recognized as a member of Pseudocercospora as delimited by Crous and Braun (2003). This publication provides an account of this occurrence and a molecular and morphological characterization of the specimen of the fungus found associated with Piper aduncum in Brazil.

Genomic DNA was extracted from pure cultures growth in liquid potato-dextrose (PD) for 1 week. Three genomic regions (Elongation Factor - EF- $1 \alpha$, Internal Transcribed Spacer - ITS and 28S rDNA Large Subunit - LSU) were sequenced. The sequences were edited with DNA Dragon (http://www.dna-dragon.com/). A BLAST search (Zhang et al. 2000) was performed to check for similarity with other sequences. The Bayesian analysis (Fig. 1) were performed with ITS dataset (TreeBASE: S13481, http:/www.treebase. org/) to confirm its placement in Pseudocercospora strictu sensu using Cladosporium cladosporioides (Fresen.) G.A. de Vries and Davidiella tassiana (De Not.) Crous \& U. Braun (GenBank accessions: AY213640 and DQ780400, respectively) as outgroup. The MrModeltest 2.3 was used to select the best nucleotide substitution model (Nylander 2004). The Bayesian analysis was performed in CIPRES Science Gateway (Miller et al. 2010; http://www.phylo.org/ index.php/portal/) by MrBayes on XSEDE. The sequences used in the study were selected from a phylogenetic tree provided in Crous et al. (2012). The sequence alignment was performed with MAFFT online version (http://mafft. cbrc.jp/alignment/server/). Samples of Piper aduncum bearing leaf spots symptoms were dried in a plant press and deposited in the herbarium at the Universidade Federal de Viçosa under the accession number VIC 31889, and a pure culture was deposited in the culture collection of the same university as COAD 1111. The colonies were described after 19 days incubated on PDA (potato dextrose-agar) and PCA (potato carrot-agar) at $25{ }^{\circ} \mathrm{C}$ under two different light regimes, $12 \mathrm{~h}$ of light and $24 \mathrm{~h}$ in the dark. The fungus structures were scraped with a scalpel from infected leaves 
Fig. 1 Phylogenetic tree based on the Bayesian analysis of ITS sequence. The highlighted clade represents Pseudocercospora sensu strictu

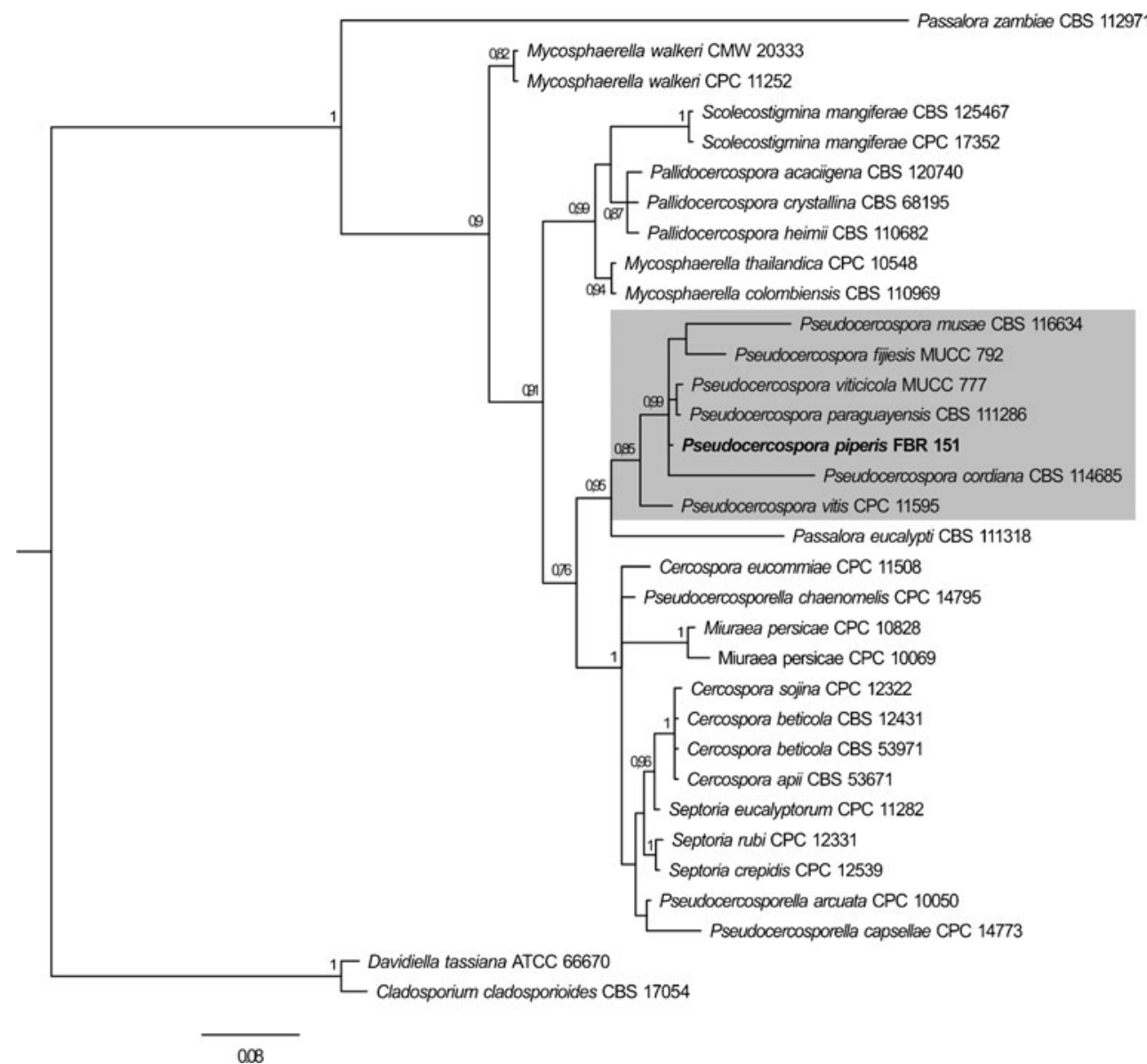

or sections were prepared and mounted in either lactophenol or lactofuchsin and examined with an Olympus BX 51 light microscope fitted with an Olympus E330 digital camera. A morphological description was elaborated and compared with descriptions of others Pseudocercospora species associated with Piperaceae found in literature.

The fungus had the following features (Fig. 2): Lesions on leaves, initially pale grey reduced to small spots less than $2.5 \mathrm{~mm}$, becoming vein-delimited and angular or occasionally circular, up to $7 \mathrm{~mm}$ diam, dark brown to black abaxially and dark grey with black edge adaxially. Internal mycelium intra and intercellular, 2-3 $\mu \mathrm{m}$ diam, branched, septate, pale olivaceous to hyaline. External mycelium arising from stomata, hypophyllous, 2.0-3.0 $\mathrm{m}$, sparingly branched, septate, pale brown, smooth. Stromata absent. Conidiophore hypophyllous, fasciculate, subcylindrical, 20-80×4.5-5 $\mu \mathrm{m}, 0-4$ septate, rarely branched, erect or decumbent, pale brown, paler towards the apex, smooth, occasionally reduced to conidiogenous cell when arising from stomata, and solitary, $525 \times 36 \mu \mathrm{m}$, reduced to the conidiogenous cell when arising from external mycelium. Conidiogenous cell terminal, integrated, holoblastic, sym-

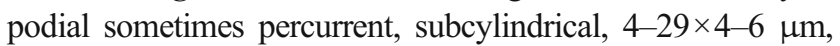
pale brown sometimes olivaceous, smooth. Conidiogenous loci indistinct. Conidia isolate, subcylindrical, straight or slightly curved, 17-65 $\times 3-5 \mu \mathrm{m}$, base obtuse, $1.5-3.5 \mu \mathrm{m}, 1-7$ septate, hilum unthickned, guttulate, pale olivaceous to pale brown, sometimes yellowish brown, occasionaly anastomosing to neighboring conidia. Colonies very slow growing $(2.53 \mathrm{~mm}$ diam. after 20 days), circular, flat to slightly convex, velvety, smoke grey to grey olivaceous, reverse smoke grey to olivaceous black, with diurnal zonation (visible only on PCA under $12 \mathrm{~h}$ light regime), not sporulating.

Among the species of fungi that have been reported in association with Piper aduncum there is one cercosporoid species, namely Pseudocercospora piperis (Patouillard) Deighton (Farr and Rossman 2013). Here we provided the first sequences deposited in GenBank for a species of Pseudocercospora associated with Piperaceae (GenBank: EF-1 $\alpha$-JX896123; ITSJX875062; LSU-JX875063). The Bayesian analysis presented here (Fig. 1) showed that P. piperis found on Piper aduncum belongs to the genus Pseudocercospora sensu strictu. Crous et al. (2012) recommended that a search for novel loci is still necessary for more robust phylogeny analysis to be produced for Pseudocercospora at the species level. There are seven species of Pseudocercospora associated with Piperaceae (Rocha et al. 2008). The morphology of the fungus on Piper aduncum matched well with $P$. piperis (Chupp 1954). It is possible that phylogenetic analyses will reveal cryptic speciation amongst the 
Fig. 2 Pseudocercospora piperis associated with Piper aduncum. a, b. Leaf spots on adaxial and abaxial leaf side, respectively, with which $P$. piperis is associated. c, d. Close up of the leaf spots located on adaxial and abaxial side, respectively. e, f. Upper view of colonies culture on PDA and PCA, respectively. g, h. Bottom view of colonies culture on PDA and PCA, respectively. i, $\mathbf{l}$. Conidia. j, m. Anastomosing conidia. $\mathbf{k}, \mathbf{n}, \mathbf{o}$. Conidiophores arising from stomata. Bars: i$\mathrm{n}=20 \mu \mathrm{m}, \mathrm{o}=50 \mu \mathrm{m}$

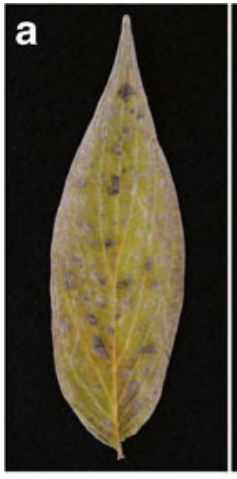

i
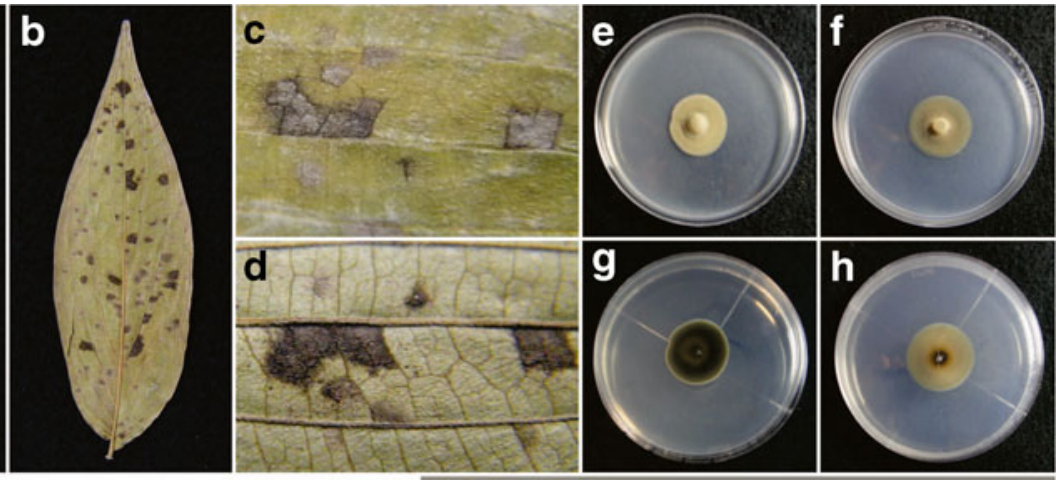

I
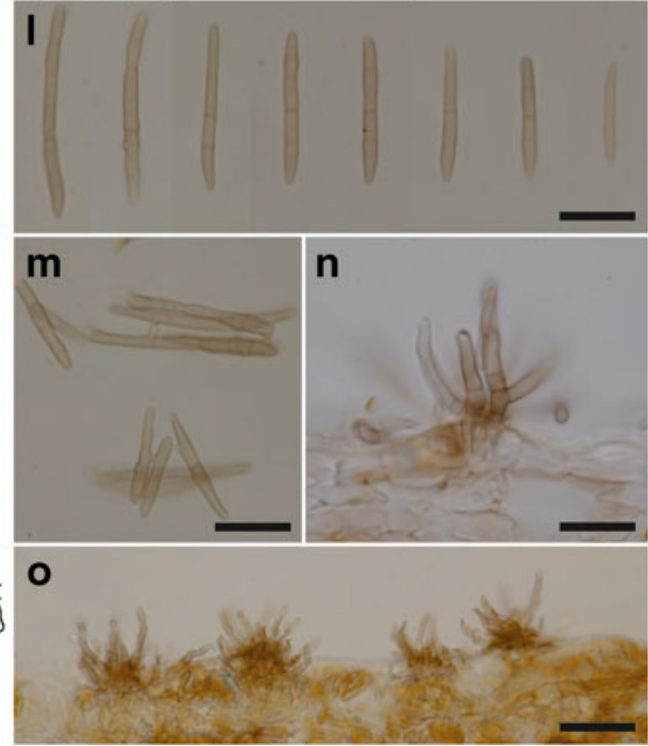

species of Pseudocercospora on Piperaceae, as several have very close morphology. As $P$. piperis was found in association with damaging spots on Piper aduncum leaves, it is possible that this fungus warrants investigation as a classical biocontrol agent against this plant in weedy situations in Papua New Guinea and elsewhere it has become invasive.

Acknowledgments The present work was supported by CAPES, Coordenação de Aperfeiçoamento de Pessoal de Nível Superior Brazil, and CNPq, Conselho Nacional de Desenvolvimento Científico e Tecnológico - Brazil

\section{References}

Chupp C (1954) A monograph of the fungus genus Cercospora. Published by the author, Ithaca

Crous PW, Braun U (2003) Mycosphaerella and its anamorphs. 1. Names published in Cercospora and Passalora. CBS biodiversity series. Centraalbureau voor Schimmelcultures, Utrecht

Crous PW, Braun U, Hunter GC, Wingfield MJ, Verkley GJM, Shin H-D, Nakashima C, Groenewald JZ (2012) Phylogenetic lineages in Pseudocercospora. Stud Mycol 75:37114
Farr DF, Rossman AY (2013) Fungal databases, Systematic mycology and microbiology laboratory, ARS, USDA. Retrieved on March 25, 2013 from http://nt.ars-grin.gov/fungaldatabases/

Hartemink AE (2010) The invasive shrub Piper aduncum in Papua New Guinea: a review. J Trop For Sci 22:202213

Lorenzi H (2000) Plantas Daninhas do Brasil: terrestres, aquáticas, parasitas e tóxicas. Instituto Plantarum, Nova Odessa

Miller MA, Pfeiffer W, Schwartz T (2010) Creating the CIPRES science gateway for inference of large phylogenetic trees in Proceedings of the Gateway Computing Environments Workshop (GCE), 14 Nov. 2010, New Orleans

Misni N, Othman H, Sulaiman S (2011) The effect of Piper aduncum Linn. (Family: Piperaceae) essential oil as aerosol spray against Aedes aegypti (L.) and Aedes albopictus Skuse. Trop Biomed 28:249-258

Morandim-Giannetti AA, Pin AR, Pietro NAS, Oliveira HC, MendesGiannini MJS, Alecio AC, Kato MJ, Oliveira JE, Furlan M (2010) Composition and antifungal activity against Candida albicans, Candida parapsilosis, Candida krusei and Cryptococcus neoformans of essencial oils from leaves of Piper and Peperonia especies. J Med Plants Res 4:18101814

Nylander JAA (2004) MrModeltest v2. Program distributed by the author. Evolutionary Biology Centre, Uppsala

Rocha FB, Soares DJ, Barreto RW (2008) Pseudocercospora species on Piperaceae from Viçosa, Minas Gerais, Brazil. Mycol Prog 7:249-252

Zhang Z, Schwartz S, Wagner L, Miller W (2000) A greedy algorithm for aligning DNA sequences. J Comput Biol 7:203-214 